\title{
Analyte Response in Laser Ablation Inductively Coupled Plasma Mass Spectrometry
}

\author{
Zhongke Wang, Bodo Hattendorf, and Detlef Günther \\ Laboratory for Inorganic Chemistry, Elemental Trace and Microanalysis, ETH Zürich, Zürich, Switzerland
}

\begin{abstract}
The dependence of analyte sensitivity and vaporization efficiency on the operating parameters of an inductively coupled plasma mass spectrometer (ICPMS) was investigated for a wide range of elements in aerosols, produced by laser ablation of silicate glass. The ion signals were recorded for different carrier gas flow rates at different plasma power for two different laser ablation systems and carrier gases. Differences in atomization efficiency and analyte sensitivity are significant for the two gases and the particle size distribution of the aerosol. Vaporization of the aerosol is enhanced when helium is used, which is attributed to a better energy-transfer from the plasma to the central channel of the ICP and a higher diffusion rate of the vaporized material. This minimizes elemental fractionation caused by sequential evaporation and reduces diffusion losses in the ICP. The sensitivity change with carrier gas flow variation is dependent on $\mathrm{m} / \mathrm{z}$ of the analyte ion and the chemical properties of the element. Elements with high vaporization temperatures reach a maximum at lower gas flow rates than easily vaporized elements. The sensitivity change is furthermore dependent on $\mathrm{m} / \mathrm{z}$ of the analyte ion, due to the mass dependence of the ion kinetic energies. The mass response curve of the ICPMS is thus not only a result of space charge effects in the ion optics but is also affected by radial diffusion of analyte ions and the mismatch between their kinetic energy after expansion in the vacuum interface and the ion optic settings. (J Am Soc Mass Spectrom 2006, 17, 641-651) (c) 2006 American Society for Mass Spectrometry
\end{abstract}

$\mathrm{T}$ The analytical performance of laser ablation inductively coupled plasma mass spectrometry (LAICPMS) analysis is determined by the amount and stoichiometry of the laser generated aerosol as well as by the degree of vaporization, atomization, and ionization of this aerosol in the ICP, and finally the transmission of the ions through the vacuum interface and the ion optics of the ICPMS. The parameters used for laser ablation determine the amount, composition, and particle size distribution of the aerosol released for a given sample [1-3]. It has been shown that wavelength, pulse duration, and fluence of the laser beam are the dominating parameters that affect the stoichiometry of the aerosol $[2,4-6]$. Nonetheless, it was found that significant variations in the elemental responses for different elements can be obtained for different ICP operating conditions and for different ICPMS systems, even when stoichiometric sampling from homogeneous (on the scale of the laser spot) samples can be achieved [7-9]. These results are currently attributed to incom-

Published online March 6, 2006

Address reprint requests to Dr. B. Hattendorf, Laboratory of Inorganic Chemistry, HC1 G105, ETH Hönggerberg, CH-8093 Zurich, Switzerland. E-mail: bodo@inorg.chem.ethz.ch plete vaporization of the aerosol in the ICP. Particularly when silicate samples are ablated, the aerosol may contain a large fraction of refractory particles and agglomerates above $150 \mathrm{~nm}$ in diameter, which are not completely atomized under typical ICP-operating conditions $[6,10,11]$.

The particle size distribution of the laser generated aerosol is in the first instance the result of a complex interaction of the laser beam with the sample material, and finally between the vaporized sample and the ambient gas [4, 12-16]. It can vary significantly between different sample matrices and even more for different types of lasers and their specific operation characteristics (wavelength, pulse duration, energy density). The effect of the ICP-operating conditions on the resulting mass spectra in the ICPMS, however, has not been explored widely. To achieve matrix independent calibration with internal standardization [17], it is required that the relative sensitivity of the analyte elements is not affected by either the matrix dependent particle size distributions or the ICP-operating conditions.

Several recent studies have highlighted the influence of the ICPMS operation on the analyte sensitivities and mass spectra acquired by LA-ICPMS. Rodushkin et al. [7] have shown that the relative 
sensitivities for different elements in different sample matrices were not only affected by the sampling process (a $266 \mathrm{~nm}$ laser was used) but also by variations in the extraction process in the vacuum interface of the ICPMS, which changed the ion kinetic energies. Wang et al. [9] have demonstrated that the sensitivities obtained for uranium and thorium were affected differently by the ICP-operating conditions.

Vaporization, atomization, and ionization of the sample aerosol in the ICP depend on the physical properties of the plasma, namely the gas kinetic temperature $\left(\mathrm{T}_{\text {gas }}\right)$, electron number density $\left(\mathrm{n}_{\mathrm{e}}\right)$ and electron temperature $\left(T_{e}\right)[18,19]$. Especially $T_{\text {gas }}$ is considered to be the dominating parameter for vaporization and atomization of the aerosol particles. It also affects the diffusion rates in the ICP and the kinetic energy of the ions sampled through the MS interface. $T_{e}$ and $n_{e}$ on the other hand determine the degree of ionization, once free atoms have been formed from the sample aerosol. $\mathrm{T}_{\text {gas }}, \mathrm{T}_{\mathrm{e}}$, and $\mathrm{n}_{\mathrm{e}}$ are together depending on the rf-power, the gas flow rates in the ICP, and the sampling depth [20]. It is, however, difficult to predict how a change in the individual parameters will influence the sensitivity and mass response curves. An increase in $T_{\text {gas, }}$ for example, will lead to an earlier onset of vaporization of the aerosol, which, assisted by a higher average $T_{\text {gas }}$, will increase the ions radial spread at the point of sampling into the mass spectrometer. As only ions that are moving close to the centerline of the sampler and skimmer orifices can be successfully transmitted to the ion optics [21], there is an increasing loss with the radial spread of the ions in the ICP (Figure 1).

Higher $\mathrm{T}_{\text {gas }}$ will furthermore lead to higher ion kinetic energies after expansion in the vacuum interface, altering the efficiency of the ion optics, which are usually tuned at a specific $\mathrm{T}_{\text {gas }}$. The magnitude of these effects is difficult to assess and it must be assumed that

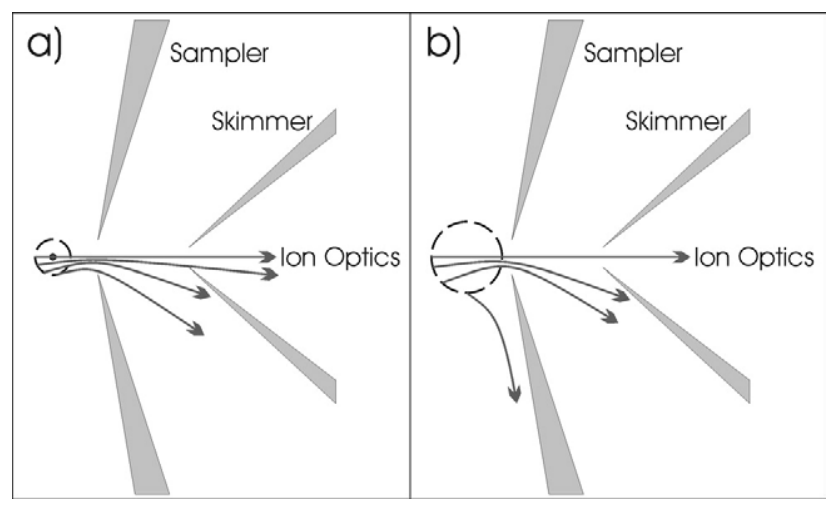

Figure 1. Effect of increasing Tgas on vaporization in the ICP and transmission of ions through the vacuum interface of the ICPMS. (a) At low Tgas, the radial spread of ions (indicated be the dashed line) allows higher transmission of ions through the vacuum interface to the ion optics. It may, however, not be sufficient to vaporize large particles (indicated by the dot). (b) At higher Tgas, all particles might get vaporized but the increased radial spread reduces the fraction of ions that can be successfully transmitted to the ion optics. the increase in sensitivity, which may be gained through a better vaporization, is to some extent mitigated by radial diffusion and/or reduced transmission in the ion optics $[22,23] . \mathrm{T}_{\mathrm{e}}$ and $\mathrm{n}_{\mathrm{e}}$ depend similarly on the ICP-operating conditions as $\mathrm{T}_{\text {gas }}$, albeit at a different magnitude [20].

Important for the atomization of the aerosol and the dissociation of molecular ions is mainly the temperature in the central channel of the ICP and finally directly in front of the sampler cone orifice [18]. The situation is more complex when helium is used as carrier gas and added to the argon in the central channel of the ICP. Laser ablation sampling in a helium atmosphere was found to increase the fraction of small particles in the aerosol, especially when a $193 \mathrm{~nm}$ laser is used [5, 13, 24]. This leads to an increased transport efficiency of the aerosol from the ablation cell to the ICP and also reduces the energy and time required for complete atomization.

Even if the gas load in the ICP is increased with the addition of helium, its higher thermal conductivity may actually enhance notably the temperature in the central channel of the ICP [25]. Furthermore, the presence of helium will affect the expansion of the plasma in the vacuum interface. Typically, we observe an increase in the pressure readings for the vacuum interface and MS with the addition of helium to the ICP, which is confirmed by visual observation of the plasma expansion (shrinking of the barrel shock and upstream movement of the Mach disk [21, 26]). It should be noted, however, that Pirani-type vacuum gauges, which are commonly used to monitor the interface pressure in commercial ICPMS instruments, are sensitive to the gas composition, making a direct assessment of the pressure change difficult. A change in the interface pressure, however, should not affect the extraction efficiency significantly provided that the skimmer orifice is still located within the zone of silence [21]. Scattering of ions during the expansion is expected to be reduced due to the smaller collision cross section and mass of helium compared to argon only.

The transmission of the ions through the ion optics and mass spectrometer depends on the ion kinetic energies, their energy spread, and space charge effects once the plasma has lost its neutral state. The most probable ion kinetic energies (MPEs) also depend on the plasma properties (plasma potential and $\mathrm{T}_{\text {gas }}$ ) $[27,28]$ and flow dynamics within the vacuum interface (which is also affected by $\mathrm{T}_{\text {gas }}$ ) [21]. It is thus of major importance to understand the specific effects of the ICP operation on the resulting mass spectra when the ICPMS is used with laser ablation sampling specifically. The MPE is a result of two individual components: the mass dependent energy gained in the expansion within the vacuum interface and a fixed component attributable to the plasma potential [29]. Increasing $\mathrm{T}_{\text {gas }}$ will cause a mass dependent increase of the energy gained during expansion but may as well lower the plasma potential [30] and cause a mass independent reduction 
of the MPE. The presence of helium may also affect the transmission through the ion optics since the ion energies may be modified differently by collisions compared to argon only as the background gas.

The wider the energy spread for ions of a given $\mathrm{m} / \mathrm{z}$ and the larger the range of MPEs of different $\mathrm{m} / \mathrm{z}$, the more difficult it is to focus all ions onto the entrance aperture of the MS for a given set of lens voltages. Modern ICPMS designs usually minimize the plasma potential to only a few volts [27, 31, 32] to eliminate unwanted spurious discharges. For high $\mathrm{m} / \mathrm{z}$, the MPE is thus mostly resulting from the expansion in the interface and the plasma potential is less important. Increasing $\mathrm{T}_{\text {gas }}$ will lead to a larger spread of the MPE for different $\mathrm{m} / \mathrm{z}$ and the transmission efficiency of a static ion lens system will affect the sensitivity for different $\mathrm{m} / \mathrm{z}$ differently.

Changes in the plasma temperature will furthermore affect $T_{e}$ and $n_{e}$, which may especially change the density of background ions (mainly $\mathrm{Ar}^{+}$) in the ion beam substantially. Space-charge can therefore become more pronounced at higher plasma temperatures and additionally suppress analyte sensitivity, especially at low $\mathrm{m} / \mathrm{z}$.

Due to the complexity and interaction of the individual parameters and furthermore because no sufficiently accurate model of the ICP exists, it is difficult to predict the influence of a specific parameter on analyte sensitivity precisely. Thus, to gain a better understanding of the effect of the ICP operating conditions on the elemental response obtained by laser ablation, this study investigates the dependence of analyte sensitivity and its relative response on the ICP-operating parameters when different particle size distributions are introduced into the ICP.

A comparison is made between element groups that have a high ( $\mathrm{Li}, \mathrm{Cs}$, and $\mathrm{Pb}$ ) and low (Be, $\mathrm{La}$, and $\mathrm{Ta}$ ) degree of vaporization in the ICP, as expressed by their vaporization index [10], and the $\mathrm{U}^{+} / \mathrm{Th}^{+}$intensity ratio. The vaporization index in [10] is a measure for the fraction of material that is successfully vaporized and ionized from a given laser generated aerosol. For elements with low vaporization index, the signal intensity measured by ICPMS is correlated with the amount of aerosol introduced into the ICP over a wide range, and there is little dependency on the particle size distribution. Elements with high vaporization index, on the other hand, show an increasing deviation in the detection efficiency by the ICPMS when the aerosol contains a large fraction of particles $>150 \mathrm{~nm}$. The $\mathrm{U}^{+} / \mathrm{Th}^{+}$ratio has recently been introduced as a viable indicator for the degree of fractionated atomization of the elements from a laser generated aerosol [33]. For non-fractionating vaporization and atomization, this intensity ratio should reflect the molar concentration ratio in the ablated material because of the similar ionization energy and close $\mathrm{m} / \mathrm{z}$ values. The results are compared to the $\mathrm{ThO}^{+} / \mathrm{Th}^{+}$ratio, which can be used as an estimate of $\mathrm{T}_{\text {gas }}[18,34]$, and the response curves obtained under different operation conditions, which can serve as an estimate for the effect of the ICP operation conditions on the kinetic energy of ions with different $\mathrm{m} / \mathrm{z}$ and the resulting mass bias of the ICPMS.

\section{Experimental}

\section{ICPMS}

The experiments were carried out using an Agilent 7500cs ICPMS (Waldbronn, Germany), which was operated with non-pressurized collision/reaction cell. No modifications were made to the instrument hardware and standard sampler and skimmer cones $(\mathrm{Pt}, 1 \mathrm{~mm}$ and $0.4 \mathrm{~mm}$ orifice size, respectively) were used. The instrument is equipped with a grounded metal shield between the load coil and the plasma torch, which reduces the capacitive coupling between the coil and the plasma and minimizes the plasma potential [32]. The ion optics were operated in so-called "soft extraction mode", i.e., applying a moderate positive potential to the first extraction lens, which should reduce space charge effects in the ion optics because the plasma stays longer in its quasi-neutral state [35]. The ion optic components were adjusted to maximum transmission, but ensuring a balanced transmission across the mass range. It should be noted that the transmission of different $\mathrm{m} / \mathrm{z}$ can be manipulated over a wide range with the ion optics arrangement used in the instrument. Thus, any tuning of the ion lenses, and the resulting mass bias, will be affected by the "personal" preferences of the operator. This should, however, not affect the general trend in the observations made here. The optimization of ion optics and torch position was carried out while ablating the SRM NIST 610 glass reference sample using a set of standard operating conditions (Table 1).

\section{Laser Ablation}

Two different laser ablation systems were used, which produce different particle size distributions from silicate materials such as the SRM NIST 610 [1]. An LSX 200 (CETAC Technologies, Omaha, NE) operating at $266 \mathrm{~nm}$ and a Geolas C (Microlas D, Göttingen, Germany) operating at $193 \mathrm{~nm}$ were used for laser ablation sampling. When ablation was carried out in an argon environment, the ablation cell was connected directly to the mass flow controller of the ICPMS. For experiments with helium as carrier gas, it was supplied via an external mass flow controller to the ablation cell and mixed to a constant flow of argon before entering the central channel of the ICP. The operating parameters are summarized in Table 1.

\section{Data Acquisition}

For each analysis, the transient signals were recorded for $120 \mathrm{~s}$ following the procedure proposed by Long- 
Table 1. Operating parameters for laser ablation and ICP-MS instruments

\begin{tabular}{|c|c|c|c|c|}
\hline ICPMS & Agilent 7500cs & Laser Ablation & GeoLas C & LSX 200 \\
\hline Rf-Power ${ }^{a}$ & $1400 \mathrm{~W}$ & Type & ArF-excimer & $\mathrm{Nd}: Y A G$ \\
\hline Sampling depth & $4 \mathrm{~mm}$ & Wavelength & $193 \mathrm{~nm}$ & $266 \mathrm{~nm}$ \\
\hline Carrier gas flow rate & & Pulse duration & $13 \mathrm{~ns}$ & $5 \mathrm{~ns}$ \\
\hline Ar-only a & $1.1 \mathrm{~L} / \mathrm{min}$ & Repetition rate & $10 \mathrm{~Hz}$ & $10 \mathrm{~Hz}$ \\
\hline $\mathrm{He} / \mathrm{Ar}^{\mathrm{a}}$ & 0.9 / 0.7 L/min & Energy density & $7 \mathrm{~J} / \mathrm{cm}^{2}$ & $7 \mathrm{~J} / \mathrm{cm}^{2}$ \\
\hline Sampler & $1 \mathrm{~mm} \mathrm{Pt}$ & Spot size & $63 \mu \mathrm{m}$ & $50 \mu \mathrm{m}$ \\
\hline Skimmer & $0.4 \mathrm{~mm} \mathrm{Pt}$ & Ablation mode & Single spot & Single spot \\
\hline \multicolumn{5}{|c|}{ Typical ion optic settings } \\
\hline Extraction lens 1 & $+4 \mathrm{~V}$ & & & \\
\hline Extraction lens 2 & $-103 \mathrm{~V}$ & & & \\
\hline Omega bias & $-48 \mathrm{~V}$ & & & \\
\hline Omegas lens & $+8.2 \mathrm{~V}$ & & & \\
\hline Cell entrance & $-34 \mathrm{~V}$ & & & \\
\hline QP focus & $0 \mathrm{~V}$ & & & \\
\hline
\end{tabular}

anitially used parameters; modified for the experiments in this study.

erich et al. [17]. The first $30 \mathrm{~s}$ were used for acquisition of the instrumental background (gas blank) followed by ablation of SRM NIST 610 for $60 \mathrm{~s}$, and another $30 \mathrm{~s}$ to monitor aerosol washout. The time resolved data were exported to a spreadsheet program that allows manual selection of the integration intervals and calculation of average background and analyte intensities. The integration intervals for the background signals were adjusted to minimize the occurrence of individual spikes, which result from single particles that are released from the transport tubing or the ablation cell occasionally, while the integration interval of the ablation signal was always $60 \mathrm{~s}$ from the first appearance of an ablation signal. Three individual measurements were carried out for each instrument setting studied. The reproducibility of the three measurements was always below $10 \%$ relative standard deviation (RSD) and in most cases better than 3\% RSD.

\section{Data Evaluation}

The changes in analyte sensitivity for different element groups and the response curve of the ICPMS were normalized and are evaluated upon their dependence on the gas flow and rf-power. The response values were calculated after normalizing the average ion signals to the respective abundance of the isotope and the molar concentration in SRM NIST 610 [36]. These response values are given in cps/ $/ \mathrm{mol} / \mathrm{g}$ instead of the often used cps/ppm and allow a better estimation of the mass bias of the ICPMS as they take into account the specific number of analyte atoms per unit mass for each element (one $\mu \mathrm{g} / \mathrm{g}$ of $\mathrm{Li}$ represents $\approx 34$ times more atoms than one $\mu \mathrm{g} / \mathrm{g}$ of $\mathrm{U})$.

\section{Results and Discussion}

\section{Operation with Argon Carrier Gas}

$266 \mathrm{~nm}$ laser ablation. Figure 2 shows typical profiles for the normalized sensitivity for two different element groups, the $\mathrm{U}^{+} / \mathrm{Th}^{+}$and $\mathrm{ThO}^{+} / \mathrm{Th}^{+}$intensity ratios in dependence on carrier gas flow rate for 1000 and 1400 $\mathrm{W}$ rf-power. Ablation was carried out at $266 \mathrm{~nm}$ with argon as carrier gas. The sensitivity of all isotopes measured continuously increases and reaches a maximum at a gas flow rate that increases with rf-power applied. Compared to $1000 \mathrm{~W}$, the maximum sensitivity is shifted by $\sim 0.1 \mathrm{~L} / \mathrm{min}$ towards higher gas flow rates at $1400 \mathrm{~W}$. Refractory elements like Be, La, and Ta always reach the maximum at lower gas flow rates than elements with low vaporization index but similar $\mathrm{m} / \mathrm{z}$. The magnitude of the intensity change is also dependent on $m / z$ and element. Low and high $m / z$ (e.g., Li and $\mathrm{Pb}$ ) show a more pronounced increase than intermediate $m / z$, and the refractory elements always show a lower gain than other elements of similar $\mathrm{m} / \mathrm{z}$. These results are in qualitative agreement with the expected effect of rf-power and gas flow rate on the $\mathrm{T}_{\text {gas }}$ in the ICP. Increasing the gas flow rate initially reduces the losses caused by diffusion (more pronounced for low $\mathrm{m} / \mathrm{z}$ ) and mismatch between the MPE and ion optic settings (more pronounced for high $\mathrm{m} / \mathrm{z}$ ). Upon surpassing a critical value, however, the vaporization and ionization efficiency is reduced and the intensities decrease. Considering the profile for $\mathrm{ThO}^{+} / \mathrm{Th}^{+}$, it is apparent that formation of oxide ions cannot account for the comparably greater loss of the refractory elements. $\mathrm{Th}^{+}$is amongst the elements with highest $\mathrm{MO}^{+}$ abundance and the $\mathrm{ThO}^{+} / \mathrm{Th}^{+}$ratio remains fairly constant at $\approx 0.3 \%$ for low gas flow rates. The presence of this plateau indicates that there is an additional process leading to formation of $\mathrm{ThO}^{+}$, which is not strongly dependent on the ICP operating conditions. Most likely, this results from oxidation of $\mathrm{Th}^{+}$in collisions with background oxygen in the vacuum interface. There is only comparably little change in the interface pressure, and thus a fairly constant supply of reactants to the expanding plasma.

Only when surpassing a gas flow rate of $1.1 \mathrm{~L} / \mathrm{min}$ at $1000 \mathrm{~W}$ and $1.3 \mathrm{~L} / \mathrm{min}$ at $1400 \mathrm{~W}$, a steep increase in the 

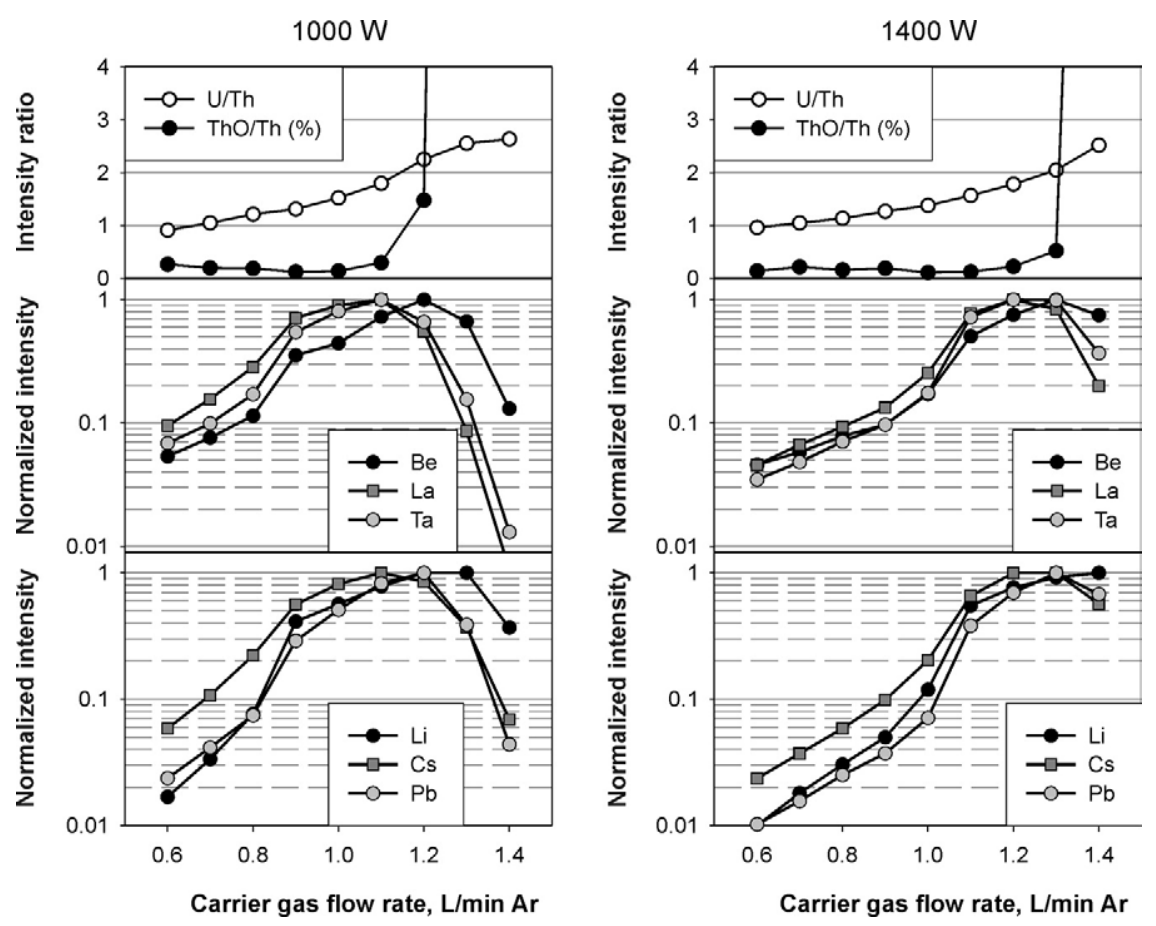

Figure 2. $\mathrm{U}^{+} / \mathrm{Th}^{+}$and $\mathrm{ThO}^{+} / \mathrm{Th}^{+}$ratio and normalized sensitivity for 1000 and $1400 \mathrm{~W}$ in dependence on carrier gas flow rate (argon) with $266 \mathrm{~nm}$ laser ablation.

$\mathrm{ThO}^{+} / \mathrm{Th}^{+}$ratio occurs, which can be related to a lower $\mathrm{T}_{\text {gas }}$ of the ICP. Before reaching this value, however, the refractory elements already show a significant reduction in sensitivity compared to elements with low vaporization indices. The different behavior of the two element groups is also reflected in the $\mathrm{U}^{+} / \mathrm{Th}^{+}$ratio and is in agreement with their respective vaporization indices [10]. The $\mathrm{U}^{+} / \mathrm{Th}^{+}$ratio steadily increases from their molar ratio of approximately one to reach values greater than two at high gas flow rates. The different profiles for the refractory and nonrefractory elements and the $\mathrm{U}^{+} / \mathrm{Th}^{+}$versus the $\mathrm{ThO}^{+} / \mathrm{Th}^{+}$ratios are thus an indication for different temperatures experienced by the sample material during and after evaporation from the aerosol particle. This difference is a likely result of the boundary layer at the particle surface, which limits the energy-transfer from the plasma towards the particle [37] and thus reduces the effective surface temperature to below $\mathrm{T}_{\text {gas. }}$. The "vaporization cloud" [38] surrounding the aerosol particle can further reduce the atomization and ionization efficiencies of vaporized material and cause additional signal suppression.

$193 \mathrm{~nm}$ laser ablation. There is no significant difference in the flow profiles when the $193 \mathrm{~nm}$ laser is used instead (Figure 3). The maximum sensitivity is obtained at essentially the same gas flow rates for all elements as with the $266 \mathrm{~nm}$ laser, and the relative increase is also similar. Slightly higher vaporization efficiency of the aerosol, however, is indicated by the smaller increase in the $\mathrm{U}^{+} / \mathrm{Th}^{+}$ratio, which might also be responsible for the 1.5- to 3-fold higher maximum intensity (as ex- plained in Table 2). This is a result of the increased fraction of particles $<150 \mathrm{~nm}$ in aerosols generated from SRM NIST 610 by this laser wavelength [15]. These particles are more readily vaporized and thus lead to a higher overall sensitivity. The fraction of particles that cannot be completely vaporized, however, is still significant and is responsible for the relative depletion of the refractory group of elements. The temperature that is relevant for the dissociation of $\mathrm{ThO}^{+}$, on the other hand, is essentially identical to when the $266 \mathrm{~nm}$ laser is used.

The response curves obtained with argon as carrier gas (Figure 5) show a pattern that is typical for ICPMS in general. Sensitivity is highest at intermediate to high $\mathrm{m} / \mathrm{z}$ and falls off significantly towards low $\mathrm{m} / \mathrm{z}$ values. This general $\mathrm{m} / \mathrm{z}$ dependency (the envelope of the response curve) is the result of all the factors that may cause mass bias: space charge effects in the ion optics, mismatch of the $\mathrm{m} / \mathrm{z}$ dependent MPE to the ion optics settings, as well as mass dependent diffusion rates in the ICP and the vacuum interface. The shift in the $\mathrm{m} / \mathrm{z}$ with highest transmission towards higher $\mathrm{m} / \mathrm{z}$ with increasing gas flow (i.e.; lower $\mathrm{T}_{\text {gas }}$ ) is consistent with a reduced MPE. The ion optics are typically optimized to provide highest sensitivity in the intermediate $\mathrm{m} / \mathrm{z}$ range, which discriminates to some extent against higher and lower $\mathrm{m} / \mathrm{z}$ (i.e.; MPE). When the MPE is reduced due to a lower plasma temperature, the high $\mathrm{m} / \mathrm{z}$ range can be transmitted more efficiently, compared to low and intermediate $\mathrm{m} / \mathrm{z}$. The gain in sensitivity for low $m / z$, however, must be a result of lower diffusion rates in the ICP and vacuum interface. It is 

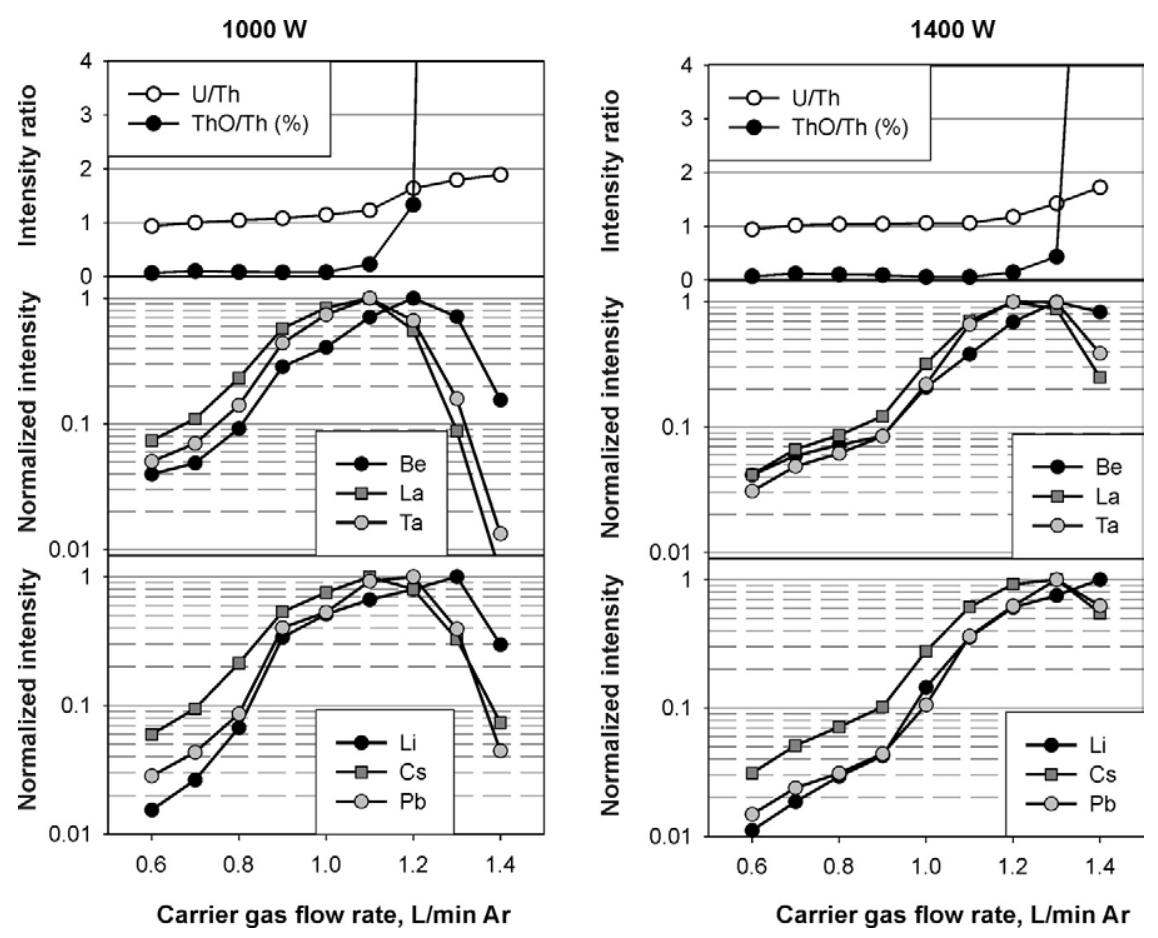

Figure 3. $\mathrm{U}^{+} / \mathrm{Th}^{+}$and $\mathrm{ThO}^{+} / \mathrm{Th}^{+}$ratio and normalized sensitivity for 1000 and $1400 \mathrm{~W}$ in dependence on carrier gas flow rate (argon) with $193 \mathrm{~nm}$ laser ablation.

interesting to note that this more than compensates for potential losses due to the increasing mismatch between the low $m / z$ MPEs at lower $\mathrm{T}_{\text {gas }}$ and the tuning of the ion optics.

The response curves in Figure 4 further show characteristic, element-specific properties. Deviations from a uniformly continuous envelope indicate that processes other than diffusion and mass bias affect the sensitivity, because both processes would lead to a more or less steady function of sensitivity on mass or $\mathrm{m} / \mathrm{z}$ with little element-specific features. These can be either caused by incomplete vaporization or ionization of the element. It will, in general, be difficult to ascribe the deviation to one process alone but several features are readily explained. Elements with high ionization energy, such as $\mathrm{Au}(\mathrm{m} / z$ 197, IE $9.2 \mathrm{eV})$, show in all cases

Table 2. Maximum response obtained for the different ablation conditions and rf-power settings, $193 \mathrm{~nm}$ data are normalized to a spot size of $50 \mu \mathrm{m}$

\begin{tabular}{|c|c|c|c|c|c|c|c|c|}
\hline \multirow[b]{3}{*}{$\lambda, \mathrm{nm}$} & \multirow[b]{3}{*}{ Gas } & \multirow[b]{3}{*}{ Rf-power } & \multicolumn{6}{|c|}{ Response, $10^{3} \mathrm{cps} / \mu \mathrm{mol} / \mathrm{g}$ and corresponding carrier gas flow, $\mathrm{L} / \mathrm{min}$} \\
\hline & & & \multicolumn{3}{|c|}{ Low vaporization index } & \multicolumn{3}{|c|}{ High vaporization index } \\
\hline & & & ${ }^{7} \mathrm{Li}$ & ${ }^{133} \mathrm{Cs}$ & ${ }^{208} \mathrm{~Pb}$ & ${ }^{9} \mathrm{Be}$ & ${ }^{139} \mathrm{La}$ & ${ }^{181} \mathrm{Ta}$ \\
\hline \multirow[t]{2}{*}{266} & $\mathrm{Ar}$ & $1000 \mathrm{~W}$ & 5.9 & 150 & 230 & 0.7 & 95 & 150 \\
\hline & & & $1.3 \mathrm{~L} / \mathrm{min}$ & $1.1 \mathrm{~L} / \mathrm{min}$ & $1.2 \mathrm{~L} / \mathrm{min}$ & $1.2 \mathrm{~L} / \mathrm{min}$ & $1.1 \mathrm{~L} / \mathrm{min}$ & $1.1 \mathrm{~L} / \mathrm{min}$ \\
\hline \multirow[t]{2}{*}{266} & $\mathrm{Ar}$ & $1400 \mathrm{~W}$ & 7.7 & 210 & 400 & 1.0 & 130 & 180 \\
\hline & & & $1.4 \mathrm{~L} / \mathrm{min}^{\mathrm{a}}$ & $1.3 \mathrm{~L} / \mathrm{min}$ & $1.3 \mathrm{~L} / \mathrm{min}$ & $1.3 \mathrm{~L} / \mathrm{min}$ & $1.2 \mathrm{~L} / \mathrm{min}$ & $1.2 \mathrm{~L} / \mathrm{min}$ \\
\hline \multirow[t]{2}{*}{193} & $\mathrm{Ar}$ & $1000 \mathrm{~W}$ & 11 & 240 & 420 & 1.5 & 210 & 360 \\
\hline & & & $1.3 \mathrm{~L} / \mathrm{min}$ & $1.1 \mathrm{~L} / \mathrm{min}$ & $1.2 \mathrm{~L} / \mathrm{min}$ & $1.2 \mathrm{~L} / \mathrm{min}$ & $1.1 \mathrm{~L} / \mathrm{min}$ & $1.1 \mathrm{~L} / \mathrm{min}$ \\
\hline \multirow[t]{2}{*}{193} & $\mathrm{Ar}$ & $1400 \mathrm{~W}$ & 14 & 320 & 590 & 1.9 & 250 & 410 \\
\hline & & & $1.4 \mathrm{~L} / \mathrm{min}^{\mathrm{a}}$ & $1.3 \mathrm{~L} / \mathrm{min}$ & $1.3 \mathrm{~L} / \mathrm{min}$ & $1.3 \mathrm{~L} / \mathrm{min}$ & $1.2 \mathrm{~L} / \mathrm{min}$ & $1.2 \mathrm{~L} / \mathrm{min}$ \\
\hline \multirow[t]{2}{*}{266} & $\mathrm{He}$ & $1000 \mathrm{~W}$ & 5.8 & 260 & 450 & 0.8 & 170 & 240 \\
\hline & & & $1.3 \mathrm{~L} / \mathrm{min}^{\mathrm{a}}$ & $1.1 \mathrm{~L} / \mathrm{min}$ & $1.3 \mathrm{~L} / \mathrm{min}^{\mathrm{a}}$ & $1.3 \mathrm{~L} / \mathrm{min}^{\mathrm{a}}$ & $0.9 \mathrm{~L} / \mathrm{min}$ & $0.9 \mathrm{~L} / \mathrm{min}$ \\
\hline \multirow[t]{2}{*}{266} & $\mathrm{He}$ & $1400 \mathrm{~W}$ & 5.1 & 270 & 320 & 0.7 & 180 & 240 \\
\hline & & & $1.3 \mathrm{~L} / \mathrm{min}^{\mathrm{a}}$ & $1.3 \mathrm{~L} / \mathrm{min}^{\mathrm{a}}$ & $1.3 \mathrm{~L} / \mathrm{min}^{\mathrm{a}}$ & 1.3L $/ \mathrm{min}^{\mathrm{a}}$ & $1.3 \mathrm{~L} / \mathrm{min}^{\mathrm{a}}$ & $1.3 \mathrm{~L} / \mathrm{min}^{\mathrm{a}}$ \\
\hline \multirow[t]{2}{*}{193} & $\mathrm{He}$ & $1000 \mathrm{~W}$ & 17 & 710 & 1000 & 2.9 & 640 & 880 \\
\hline & & & $1.3 \mathrm{~L} / \mathrm{min}^{\mathrm{a}}$ & $0.9 \mathrm{~L} / \mathrm{min}$ & 1.3L $/ \mathrm{min}^{\mathrm{a}}$ & $1.3 \mathrm{~L} / \mathrm{min}^{\mathrm{a}}$ & $0.9 \mathrm{~L} / \mathrm{min}$ & $0.9 \mathrm{~L} / \mathrm{min}$ \\
\hline \multirow[t]{2}{*}{193} & $\mathrm{He}$ & $1400 \mathrm{~W}$ & 16 & 810 & 880 & 2.6 & 710 & 1100 \\
\hline & & & $1.3 \mathrm{~L} / \mathrm{min}^{\mathrm{a}}$ & $1.3 \mathrm{~L} / \mathrm{min}^{\mathrm{a}}$ & $1.3 \mathrm{~L} / \mathrm{min}^{\mathrm{a}}$ & $1.3 \mathrm{~L} / \mathrm{min}^{\mathrm{a}}$ & $1.3 \mathrm{~L} / \mathrm{min}^{\mathrm{a}}$ & $1.3 \mathrm{~L} / \mathrm{min}^{\mathrm{a}}$ \\
\hline
\end{tabular}

${ }^{a}$ Maximum sensitivity is obtained at or above highest gas flow rate used. 


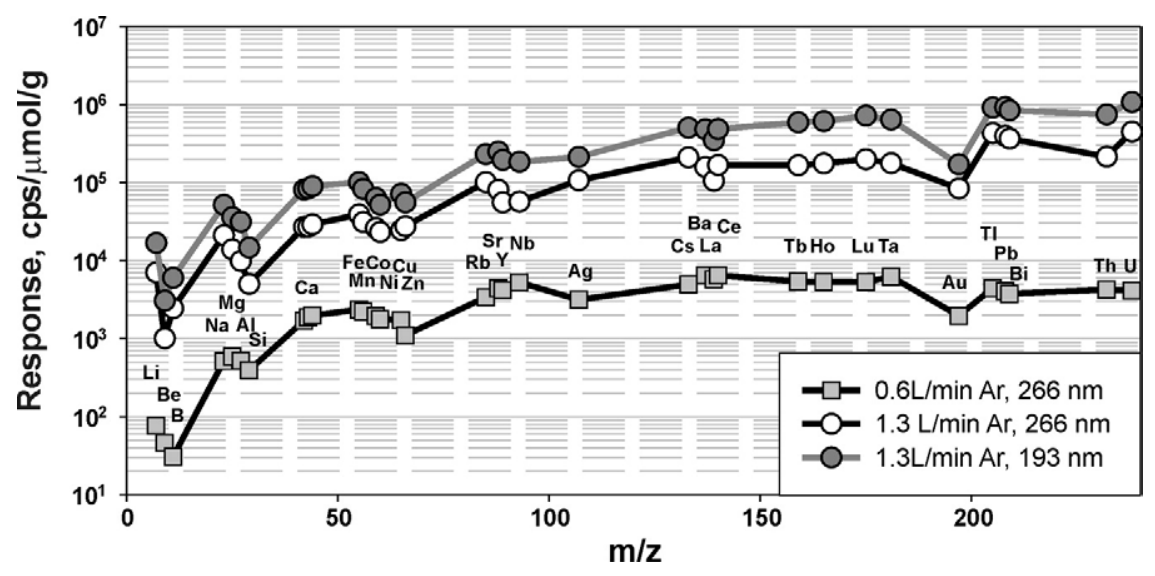

Figure 4. Response curves of the ICPMS using different flow rates of argon as carrier gas with an rf-power of 1400 W. Not normalized to identical spot sizes.

a significantly lower response than would be expected from interpolation between elements that are close in $m / z$ but have lower ionization energy, like Ta $(m / z ~ 181$, IE $7.9 \mathrm{eV})$ or Tl $(m / z 205$, IE $6.1 \mathrm{eV})$. On the other hand, elements with similar ionization energies may show significant differences in their relative response due to incomplete vaporization like $\mathrm{Th}(\mathrm{m} / \mathrm{z}$ 232, IE $6.1 \mathrm{eV})$ relative to $\mathrm{U}(\mathrm{m} / \mathrm{z} 238$, IE $6.1 \mathrm{eV})$ or $\mathrm{La}$ $(\mathrm{m} / \mathrm{z} 139$, IE $5.6 \mathrm{eV})$ relative to $\mathrm{Ce}(\mathrm{m} / \mathrm{z} 140$, IE $5.5 \mathrm{eV})$. In all these cases, the relative sensitivity for elements with higher ionization energy $(\mathrm{Au})$ or lower vaporization efficiency (La, Th) decreases with increasing gas flow rate or lower rf-power, corresponding to decreasing $\mathrm{T}_{\text {gas }}$ and $\mathrm{T}_{\mathrm{e}}$.

There are, however, also variations that cannot be explained in the same manner. Comparing $\mathrm{Li}(m / z 7), \mathrm{Be}$ $(\mathrm{m} / \mathrm{z} 9)$, and B $(\mathrm{m} / \mathrm{z} 11)$, for example, it is obvious that the relative sensitivity of $\mathrm{Li}$ and $\mathrm{B}$ changes in accordance to the respective ionization energies (5.4 versus $8.3 \mathrm{eV}$ ), i.e.; the sensitivity of $B$ is lower and shows a smaller increase with increasing gas flow rate. Be, on the other hand, shows a higher sensitivity than B at low carrier gas flow rates, despite its higher ionization energy $(9.3$ $\mathrm{eV})$. A similar situation is seen for $\mathrm{Mg}(\mathrm{m} / \mathrm{z} 25)$ and $\mathrm{Na}$ $(\mathrm{m} / \mathrm{z} 23)$, where the low carrier gas flow rate yields a higher sensitivity for $\mathrm{Mg}$ even though its ionization energy is significantly higher than that of $\mathrm{Na}$ (7.6 versus $5.1 \mathrm{eV})$. Even though spectral interferences from doubly charged ions may increase at low carrier gas flow rates, it is unlikely that doubly charged ${ }^{18} \mathrm{O},{ }^{50} \mathrm{Ti},{ }^{50} \mathrm{~V}$, or ${ }^{50} \mathrm{Cr}$, respectively, are formed in the ICP at a level that could cause such high deviation at $m / z 9$ or 25 . This apparent contradiction may be a result of a convolution of ionization efficiencies with vaporization and diffusion of the individual elements. Considering the flow profiles for these elements it is apparent that $\mathrm{Be}$ and $\mathrm{Mg}$ belong to the group of elements with higher vaporization index. The delayed vaporization of these elements thus reduces the loss due to diffusion in the ICP.

\section{Operation with Helium Carrier Gas}

$266 \mathrm{~nm}$ laser ablation. When helium is used as carrier ga, it is introduced to the central channel of the ICP after addition of $0.7 \mathrm{~L} / \mathrm{min}$ of argon for stable plasma operation. The helium flow rate was varied between 0.5 and $1.3 \mathrm{~L} / \mathrm{min}$ so that the total flow in the central channel can exceed the total gas flow rate used in the argon only plasma significantly. It should be noted that the particle size distribution obtained for the $266 \mathrm{~nm}$ laser in helium shows a slight increase in the fraction of small particles but does, in general, not differ significantly from the one obtained in argon [1]. Accordingly, slightly higher analyte sensitivities are obtained when helium is used (Table 2). At $1400 \mathrm{~W}$ rf-power the maximum sensitivity could not even be reached at a helium gas flow rate of $1.3 \mathrm{~L} / \mathrm{min}$ (corresponding to a total gas load in the central channel of $2 \mathrm{~L} / \mathrm{min}$ ). A significant difference compared to operation with argon only, however, is the smaller variation of sensitivity when the gas flow rate is increased (Figures 5 and 6). At $1000 \mathrm{~W}$ rf-power, the sensitivity changes by less than a factor of three when increasing the helium gas flow rate from 0.5 to 1.3 $\mathrm{L} / \mathrm{min}$, while the variation is at least an order of magnitude for operation with argon only. On the other hand, the difference in gas flow rates where sensitivities of the different element groups maximum is $\sim 0.3$ $\mathrm{L} / \mathrm{min}$ at $1000 \mathrm{~W}$ rf-power, which is greater than in argon only. The $\mathrm{ThO}^{+} / \mathrm{Th}^{+}$ratio shows a fairly smooth increase after a flow rate of $0.8 \mathrm{~L} / \mathrm{min}$ is applied. Operation at $1400 \mathrm{~W}$ RF-power would require even higher helium flow rates than $1.3 \mathrm{~L} / \mathrm{min}$ to achieve the highest analyte sensitivity, and the $\mathrm{ThO}^{+} / \mathrm{Th}^{+}$ratio remains fairly constant at $0.3 \%$ for the entire range of gas flow rates used.

The $\mathrm{U}^{+} / \mathrm{Th}^{+}$intensity ratio, though, shows a remarkable offset from the expected value of one even for the lowest helium flow rates used. The variability with flow rate, however, is significantly smaller for both 

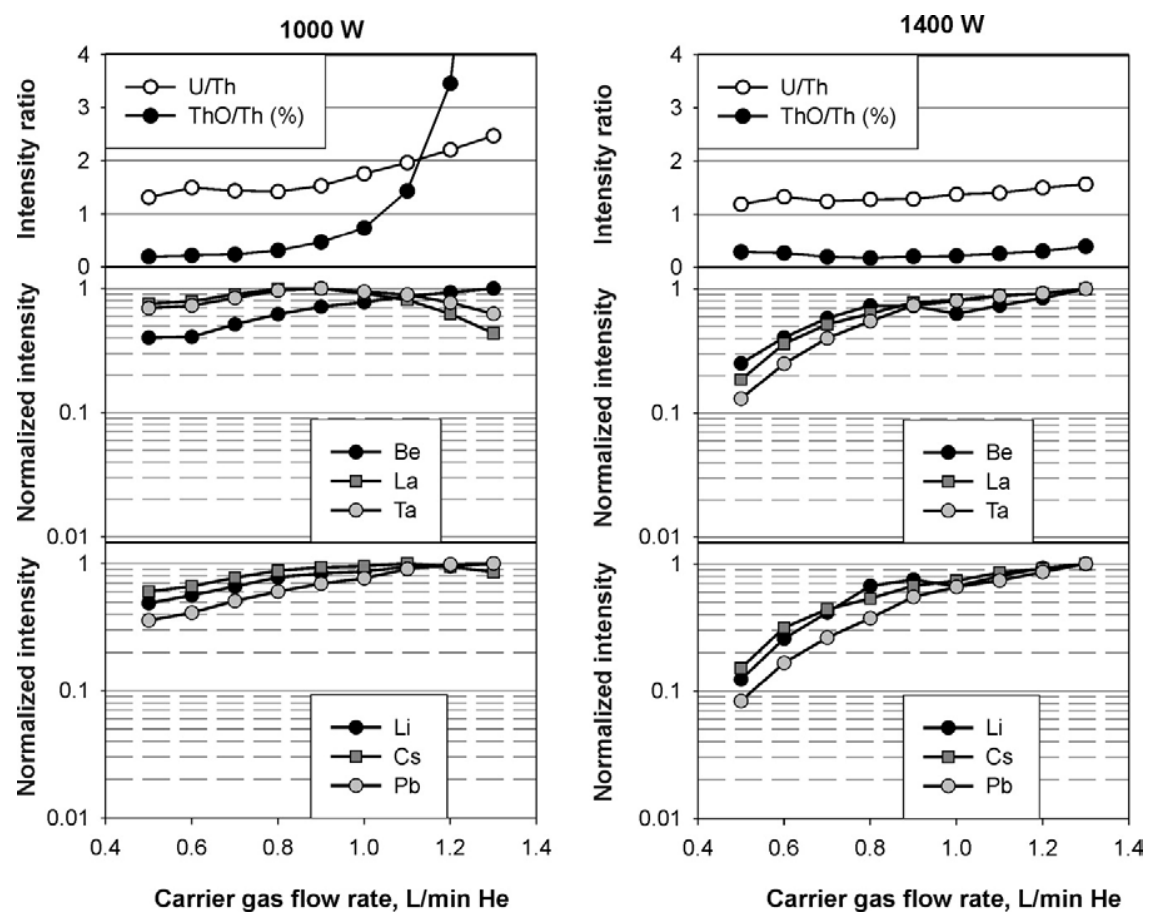

Figure 5. $\mathrm{U}^{+} / \mathrm{Th}^{+}$and $\mathrm{ThO}^{+} / \mathrm{Th}^{+}$ratio and normalized sensitivity for 1000 and $1400 \mathrm{~W}$ in dependence on carrier gas flow rate (helium) with $266 \mathrm{~nm}$ laser ablation.

rf-power settings than when argon is used as carrier gas.

$193 \mathrm{~nm}$ laser ablation. The main difference that is observed when the $193 \mathrm{~nm}$ laser is used is a 3 to 4 times higher maximum sensitivity for all isotopes (Table 2) and a better agreement of the $\mathrm{U}^{+} / \mathrm{Th}^{+}$ratio to the expected value (Figure 6). The profiles of normalized sensitivities and $\mathrm{ThO}^{+} / \mathrm{Th}^{+}$ratios, on the other hand, are very similar to those obtained using the $266 \mathrm{~nm}$ laser ablation system with helium. The higher sensitivity and the lower $\mathrm{U}^{+} / \mathrm{Th}^{+}$ratio are most likely ex-
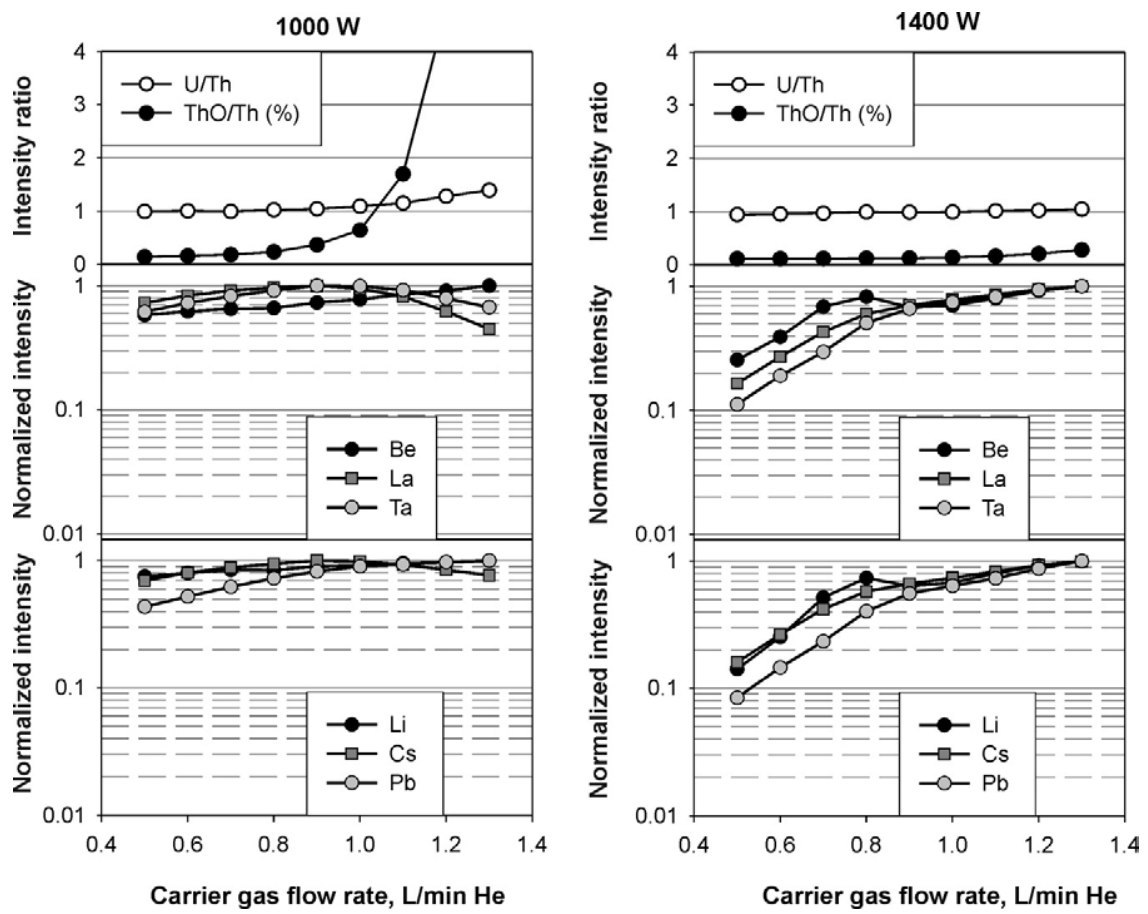

Figure 6. $\mathrm{U}^{+} / \mathrm{Th}^{+}$and $\mathrm{ThO}^{+} / \mathrm{Th}^{+}$ratio and normalized sensitivity for 1000 and $1400 \mathrm{~W}$ in dependence on carrier gas flow rate (helium) with $193 \mathrm{~nm}$ laser ablation. 
plained by the smaller fraction of particles $>150 \mathrm{~nm}$ present in the aerosol $[1,10]$. This allows higher vaporization efficiency for the aerosol generated by the combination $193 \mathrm{~nm}$ laser with helium as carrier gas.

These observations indicate that vaporization occurs more efficiently when helium is present in the ICP. Especially when considering the data for $266 \mathrm{~nm}$, where the particle size distribution is similar in helium and argon, the presence of helium leads to significantly higher sensitivity for elements with high vaporization index for a similar $\mathrm{U}^{+} / \mathrm{Th}^{+}$ratio. The higher thermal conductivity of helium compared to argon apparently more than compensates for the additional gas load applied. Thus, the addition of helium does not reduce $\mathrm{T}_{\text {gas }}$ in the central channel substantially. A similar mean $\mathrm{T}_{\text {gas }}$ in the central channel for operation with argon + helium compared to argon only is supported by dependence of the $\mathrm{ThO}^{+} / \mathrm{Th}^{+}$ratios on carrier gas flow rate. For $1000 \mathrm{~W}$ rf-power, the ratio is similar and below $0.3 \%$ for $1.1 \mathrm{~L} / \mathrm{min}$ with argon only and $0.9 \mathrm{~L} / \mathrm{min}$ helium plus $0.7 \mathrm{~L} / \mathrm{min}$ argon for both lasers. At $1400 \mathrm{~W}$ rf-power the ratios start to increase at $0.2 \mathrm{~L} / \mathrm{min}$ (argon) and $0.4 \mathrm{~L} / \mathrm{min}$ (helium) higher flow rates, respectively. These results and the relative change of the gas flow rate at which maximum sensitivity is obtained indicate that a 0.2 to $0.3 \mathrm{~L} / \mathrm{min}$ increase of the helium gas flow rate has a similar effect on the plasma temperature like an increase of $0.1 \mathrm{~L} / \mathrm{min}$ of argon.

As the higher vaporization efficiency when using helium and the $266 \mathrm{~nm}$ laser cannot be explained by a higher average temperature in the central channel or a lower fraction of large particles, it is probably caused by a combination of more efficient heat transfer to the surface of the aerosol particles due to the higher thermal conductivity, and also a faster transport of vapor from the vicinity of the particle [37].

When choosing operating parameters that provide optimum performance with respect to sensitivity and vaporization, there is no considerable change in the mass bias of the instrument for using only argon or and argon/helium mixture in the central channel of the ICP. When choosing operating conditions where atomization-related fractionation is minimized (i.e., robust operating conditions) we observe a rather uniform increase in sensitivity across the entire mass range (Figure 7). The change in the relative sensitivities ranges from 2.1 to 3.8 for $193 \mathrm{~nm}$ laser ablation, respectively, (266 nm: 0.9 to 1.7). The largest difference is found in the intermediate $\mathrm{m} / \mathrm{z}$ range, the smallest for low $\mathrm{m} / \mathrm{z}$. This is in agreement with a comparable average plasma temperature in both cases and higher diffusion rates in helium.

\section{Features in the Helium Gas Flow Profiles}

In the sensitivity profiles in helium for $1400 \mathrm{~W}$ (Figures 5 and 6, right graph), one can note that the low $\mathrm{m} / \mathrm{z}$ isotopes show a second peak at a gas flow of $0.9 \mathrm{~L} / \mathrm{min}$ for $266 \mathrm{~nm}$ ablation and $0.8 \mathrm{~L} / \mathrm{min}$ for $193 \mathrm{~nm}$ ablation. At this flow rate, one can also note a change in the slope for high $\mathrm{m} / \mathrm{z}$ isotopes. The magnitude of the change is only depending on $\mathrm{m} / \mathrm{z}$. The cause for this dramatic change in the mass response curve, however, cannot be explained yet. The abruptness of occurrence and the mass dependence of this effect hint at a sudden disturbance of the ion beam by scattering processes in the interface or ion optics. It might be caused by the increase of the interface pressure due to a lower plasma temperature and a higher concentration of helium. At increasing interface pressure, the Mach-disk [21] may shift close enough to the skimmer tip to disturb the free expansion. There might also be a secondary discharge igniting when the plasma potential and interface pressure reach a critical value, which leads to increased scattering of ions [26]. There is, however, no detectable change in the relative yields for ions with low and high ionization energy, which indicates that if a secondary discharge is present, it is too weak to change the ion density in the expanding plasma significantly.

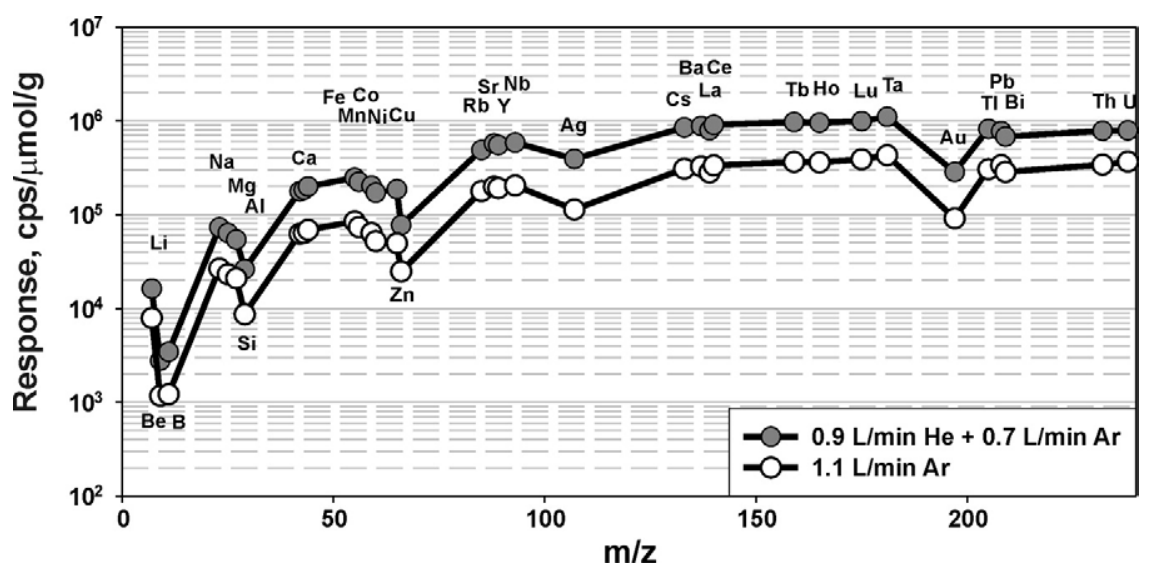

Figure 7. Response curves for robust ICP operating conditions when using only argon and helium plus argon in the central channel of the ICPMS; $1400 \mathrm{~W}$ rf-Power, $193 \mathrm{~nm}$ laser ablation 


\section{Conclusions}

The trends in optimization of the ICPMS for laser ablation sampling show no significant differences when using 193 and $266 \mathrm{~nm}$ laser wavelengths, respectively. The dependence of sensitivity and atomization efficiency on carrier gas flow rate leads to almost identical profiles for a given rf-power. Major differences lie in the analyte sensitivities that are achieved, and the vaporization and atomization efficiency of the laser generated aerosol. Higher sensitivities can be obtained when the aerosol contains mainly small particles $(<150 \mathrm{~nm}$ for silicate), which are atomized efficiently. Atomization can, to some extent, be enhanced by applying higher rf-power or lower gas flow rates, i.e., by increasing $\mathrm{T}_{\text {gas }}$ in the central channel of the ICP. This will, however, also lead to increased diffusion of analyte atoms and ions out of the region sampled by the vacuum interface of the ICPMS. The abundance of stable molecular ions, such as $\mathrm{ThO}^{+}$, is relatively constant over a wide range of plasma conditions. The critical gas flow rate, where their abundance increases remarkably, is only dependent upon the RF-power applied but independent of the particle size distribution of the aerosol and carrier gas. The plateau region in the $\mathrm{ThO}^{+} / \mathrm{Th}^{+}$profiles is most likely a result of a fairly constant reaction rate of $\mathrm{Th}^{+}$ with background oxygen in the vacuum interface.

Notable differences occur in the gas flow profiles for elements with high and low vaporization index, respectively, and for different particle size distributions. Elements with high vaporization index always reach maximum sensitivity at lower gas flow rates than elements with low vaporization index. This implies that the processes involving free atoms and molecules (i.e., ionization and dissociation of molecules or molecular ions) and evaporation of the aerosol particles are determined by different effective temperatures. It is obvious that particle evaporation and atomization can be accelerated by adding helium to the plasma. This is most likely due to better energy-transfer to the central channel of the ICP, and faster transport of vapor away from the particle surface.

For ablation with $266 \mathrm{~nm}$, the aerosol contains a significant fraction of particles that can only be vaporized using high plasma temperatures. This increases diffusion losses whenever the ICP operating conditions are adjusted to minimize fractionation in the ion source. When, in contrast, the ICP is optimized for maximum sensitivity, selective vaporization is likely to occur. The particle size distribution is also dependent on the sample matrix and ablation conditions. The latter is especially important when ablation is carried out by continuous translation of the sample under the laser beam (so called raster or scanning mode), where the fraction of large particles remains constantly high [4]. In such a case, selective vaporization will lead to analytical artifacts when the sample matrix is different from the calibration standards, and matrix independent calibration is impossible. To improve the analytical perfor- mance of LA-ICPMS in this situation, it would be necessary to either reduce the radial spread of the ions inside the ICP or to increase the area sampled through the vacuum interface and ion optics of the MS. However, even though it might be possible to increase the sampling efficiency of the interface by either larger apertures or even by ion focusing within the ICP, this will always lead to a relatively greater increase in the density of $\mathrm{Ar}^{+}$ions and cause space charge effects to become even more pronounced.

The only viable approach is thus to ensure that (1) the laser generated aerosol contains only particles that can be vaporized completely, and (2) that the vapor and ions generated in the ICP do not expand out of the plasma zone that is transmitted through the vacuum interface.

The highest atomization efficiency and analyte sensitivity for silicate samples is, accordingly, achieved using the $193 \mathrm{~nm}$ laser for ablation and helium as the carrier gas. This combination produces an aerosol that does not contain a significant fraction of particles $>150$ $\mathrm{nm}$, and the aerosol can be vaporized within a very narrow range of axial positions, minimizing analyte loss by the ions' radial spread within the ICP.

In general, when optimizing the ICPMS for operation with laser ablation sampling, the focus should be laid on reducing fractionation within the ion source by monitoring for example the $\mathrm{U}^{+} / \mathrm{Th}^{+}$ratio than to focus solely on analyte sensitivity. Even with $266 \mathrm{~nm}$ laser ablation and argon as carrier gas, the difference in sensitivity is typically within less than a factor of two, which in most cases has little impact on the attainable limits of detection but certainly improves the reliability of the analytical data.

\section{Acknowledgments}

This work has been supported through funding by the World Laboratory Lausanne, the ETH Zürich and the Swiss National Science Foundation. The authors highly appreciate very valuable comments of the reviewers that have helped to improve this manuscript.

\section{References}

1. Horn, I.; Günther, D. The influence of ablation carrier gasses Ar, He, and $\mathrm{Ne}$ on the particle size distribution and transport efficiencies of laser ablation-induced aerosols: Implications for LA-ICP-MS. Appl. Surf. Sci. 2003, 207, 144-157.

2. Koch, J.; von Bohlen, A.; Hergenröder, R.; Niemax, K. Particle size distributions and compositions of aerosols produced by near-IR femtoand nanosecond laser ablation of brass. J. Anal. At. Spectrom. 2004, 19, 267-272.

3. Poitrasson, F.; Mao, X. L.; Mao, S. S.; Freydier, R.; Russo, R. E. Comparison of ultraviolet femtosecond and nanosecond laser ablation inductively coupled plasma mass spectrometry analysis in glass, monazite, and zircon. Anal. Chem. 2003, 75, 6184-6190.

4. Guillong, M.; Günther, D. Effect of particle size distribution on ICPinduced elemental fractionation in laser ablation-inductively coupled plasma-mass spectrometry. J. Anal. At. Spectrom. 2002, 17, 831-837.

5. Günther, D.; Frischknecht, R.; Heinrich, C. A.; Kahlert, H. J. Capabilities of an Argon Fluoride $193 \mathrm{~nm}$ excimer laser for laser ablation inductively coupled plasma mass spectrometry microanalysis of geological materials. J. Anal. At. Spectrom. 1997, 12, 939-944.

6. Kuhn, H. R.; Günther, D. Laser ablation-ICP-MS: Particle size dependent elemental composition studies on filter-collected and online measured aerosols from glass. J. Anal. At. Spectrom. 2004, 19, 1158-1164. 
7. Rodushkin, I.; Axelsson, M. D.; Malinovsky, D.; Baxter, D. C. Analyteand matrix-dependent elemental response variations in laser ablation inductively coupled plasma mass spectrometry. Part 1 . The roles of plasma and ion sampling conditions. J. Anal. At. Spectrom. 2002, 17, 1223-1230.

8. Günther, D.; Hattendorf, B. Solid sample analysis using laser ablation inductively coupled plasma mass spectrometry. TRAC-Trends Anal. Chem. 2005, 24, 255-265.

9. Wang, Z.; Hattendorf, B.; Ramseier, M.; Guillong, M.; Günther, D. Studies on analyte response for uranium and thorium in dependence of operating parameters in LA-ICP-MS. ICP-Inf. Newslett. 2004, 30, 10421046.

10. Kuhn, H. R. Guillong, M.; Günther, D. Size-related vaporization and ionization of laser-induced glass particles in the inductively coupled plasma. Anal. Bioanal. Chem. 2004, 378, 1069-1074.

11. Aeschliman, D. B.; Bajic, S. J.; Baldwin, D. P.; Houk, R. S. High-speed digital photographic study of an inductively coupled plasma during laser ablation: Comparison of dried solution aerosols from a microconcentric nebulizer and solid particles from laser ablation. J. Anal. At. Spectrom. 2003, 18, 1008-1014.

12. Niemax, K. Laser ablation-reflections on a very complex technique for solid sampling. Fresenius J. Anal. Chem. 2001, 370, 332-340.

13. Eggins, S. M.; Kinsley, L. P. J.; Shelley, J. M. G. Deposition and element fractionation processes during atmospheric pressure laser sampling for analysis by ICP-MS. Appl. Surf. Sci. 1998, 129, 278-286.

14. Kuhn, H. R.; Günther, D. Elemental fractionation studies in laser ablation inductively coupled plasma mass spectrometry on laser-induced brass aerosols. Anal. Chem. 2003, 75, 747-753.

15. Horn, I.; Guillong, M.; Günther, D. Wavelength dependant ablation rates for metals and silicate glasses using homogenized laser beam profiles-implications for LA-ICP-MS. Appl. Surf. Sci. 2001, 182, 91-102.

16. Margetic, V.; Pakulev, A.; Stockhaus, A.; Bolshov, M.; Niemax, K.; Hergenröder, R. A comparison of nanosecond and femtosecond laserinduced plasma spectroscopy of brass samples. Spectrochim. Acta B 2000, 55, 1771-1785.

17. Longerich, H. P.; Jackson, S. E.; Günther, D. Laser ablation inductively coupled plasma mass spectrometric transient signal data acquisition and analyte concentration calculation. J. Anal. At. Spectrom. 1996, 11, 899-904.

18. Houk, R. S.; Praphairaksit, N. Dissociation of polyatomic ions in the inductively coupled plasma. Spectrochim. Acta B 2001, 56, 1069-1096.

19. Wilson, D. A.; Vickers, G. H.; Hieftje, G. M. Ionization temperatures on the inductively coupled plasma determined by mass spectrometry. Appl. Spectrosc. 1987, 41, 875-880.

20. Lehn, S. A.; Warner, K. A.; Huang, M.; Hieftje, G. M. Effect of an inductively coupled plasma mass spectrometry sampler interface on electron temperature, electron number density, gas-kinetic temperature, and analyte emission intensity upstream in the plasma. Spectrochim. Acta B 2002, 57, 1739-1751.

21. Douglas, D. J.; French, J. B. Gas-dynamics of the inductively coupled plasma mass-spectrometry interface. J. Anal. At. Spectrom. 1988, 3, 743-747.
22. Dziewatkoski, M. P.; Daniels, L. B.; Olesik, J. W. Time resolved inductively coupled plasma mass spectrometry measurements with individual, monodisperse drop sample introduction. Anal. Chem. 1996, $68,1101-1109$

23. Macedone, J. H.; Mills, A. A.; Farnsworth, P. B. Optical measurements of ion trajectories through the vacuum interface of an inductively coupled plasma mass spectrometer. Appl. Spectrosc. 2004, 58, 463-467.

24. Guillong, M.; Horn, I.; Günther, D. A comparison of 266 nm, 213 nm, and $193 \mathrm{~nm}$ produced from a single solid state Nd:YAG laser for laser ablation ICP-MS. J. Anal. At. Spectrom. 2003, 18, 1224-1230.

25. Sesi, N. N.; Mackenzie, A.; Shanks, K. E.; Yang, P. Y.; Hieftje, G. M.Fundamental studies of mixed-gas inductively coupled plasmas. Spectrochim. Acta B 1994, 49, 1259-1282.

26. Niu, H.; Houk, R. S. R. Fundamental aspects of ion extraction in inductively coupled plasma mass spectrometry. Spectrochim. Acta B 1996, 51, 779-815.

27. Douglas, D. J.; French, J. B. An improved interface for inductively coupled plasma mass spectrometry ICP-MS. Spectrochim. Acta B 1986, 41, 197-204.

28. Tanner, S. D. Plasma temperature from ion kinetic energies and implications for the source of diatomic ions in the inductively coupled plasma mass spectrometry. J. Anal. At. Spectrom. 1993, 8, 891-897.

29. Tanner, S. D.; Douglas, D. J.; French, J. B. Gas and ion dynamics of a three-aperture vacuum interface for inductively coupled plasma mass spectrometry. Appl. Spectrosc. 1994, 48, 1373-1378.

30. Olivares, J. A.; Houk, R. S. Ion sampling for inductively coupled plasma mass spectrometry. Anal. Chem. 1985, 57, 2674-2679.

31. Turner, P.; Merren, T.; Speakman, J.; Haines, C. Interface studies in the ICP-MS spectrometer. In Plasma Source Spectrometry. Developments and Applications; Royal Society of Chemistry: Cambridge, 1997; pp 28-34.

32. Sakata, K.; Kawabata, K. Reduction of fundamental polyatomic ions in inductively coupled plasma mass spectrometry. Spectrochim. Acta B 1994, 49, 1027.

33. Hattendorf, B.; Latkoczy, C.; Günther, D. Laser ablation-ICPMS. Anal. Chem. 2003, 75, 341A-347A.

34. Evans, E. H.; Ebdon, L.; Rowley, L. Comparative study of the determination of equilibrium dissociation temperature in inductively coupled plasma-mass spectrometry. Spectrochim. Acta B 2002, 57, 741-754.

35. Sakata, K.; Yamada, N. Sugiyama, N. Ion trajectory simulation of inductively coupled plasma mass spectrometry based on plasmainterface behavior. Spectrochim. Acta B 2001, 56, 1249-1261.

36. Pearce, N. J. G.; Perkins, W. T.; Westgate, J. A.; Gorton, M. P.; Jackson, S. E.; Neal, C. R.; Chenery, S. P. A compilation of new and published major and trace element data for NIST SRM 610 and NIST SRM 612 glass reference materials. Geostand. Newsl. 1997, 21, 115-144.

37. L'vov, B. V. A physical approach to the interpretation of the mechanisms and kinetics of analyte release in electrothermal atomic absorption spectrometry. Spectrochim. Acta B 2001, 56, 1503-1521.

38. Olesik, J. W.; Fister, J. C. III. Incompletely desolvated droplets in argon inductively coupled plasmas: Their number, original size, and effect on emission intensities. Spectrochim. Acta B 1991, 46, 851-861. 